\title{
Elevation of HRPE773 (ZG16B) expression in amnion at term and in human ectocervical cell lines treated with inflammatory mediators is consistent with a function in innate immunity \\ Hayhurst $\mathrm{R}^{1}$, Hibbert $\mathrm{N}^{1}$, Frew $\mathrm{L}^{1}$, Stock $\mathrm{SJ}^{1}$, Riley $\mathrm{SC}^{1}$, Morley $\mathrm{SD}^{2}$ \\ ${ }^{1}$ Centre for Reproductive Health, Queen's Medical Research Institute, University of Edinburgh, EH16 4TJ, UK and ${ }^{2}$ Division of Health Sciences, Chancellor's Building, University of Edinburgh, EH16 1SB, UK
}

\section{Introduction}

- Labour is an inflammatory process, mediated via molecules of the innate immune response, including Interleukin-1 $\beta$ (IL-1 $\beta$ ).

- Premature activation of these inflammatory pathways, following infection for example, is associated with complications of pregnancy including preterm birth (<37 weeks gestation) (1).

- HRPE773 has been proposed to have an antimicrobial function owing to its localisation to the secretory epithelium of several tissues, including the human female reproductive tract (2).

-We therefore hypothesised that HRPE773 expression may be regulated during human labour by inflammatory stimuli.

\section{Methods}

- Tissue samples of term human amnion, chorio-decidua, placenta, myometrium \& cervix from;

i. Labour (spontaneous vaginal delivery $>40$ weeks gestation)

ii. Non-labour (elective caesarean section 39-43 weeks gestation)

were obtained through the Edinburgh Reproductive Tissue Biobank (ERTBB) with ethical approval of West of Scotland Research Ethics Service.

- Ectocervical (ECT1/E6E7) \& endocervical (END1/E6E7) cell lines were treated (24 hrs) with; i. IL-1 $\beta$

ii. Lipopolysaccharide (LPS)

iii. No treatment (control)

- HRPE773 mRNA expression was determined in;

i. Labour relative to non-labour samples

ii. Treated cervical cell lines relative to an untreated control

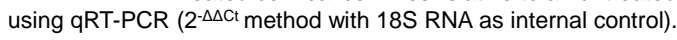

- The cell specific localisation of HRPE773 protein in human foetal membranes, placenta, myometrium and cervix was determined using immunohistochemistry.

\section{Results}

$1 \mathrm{~A}$

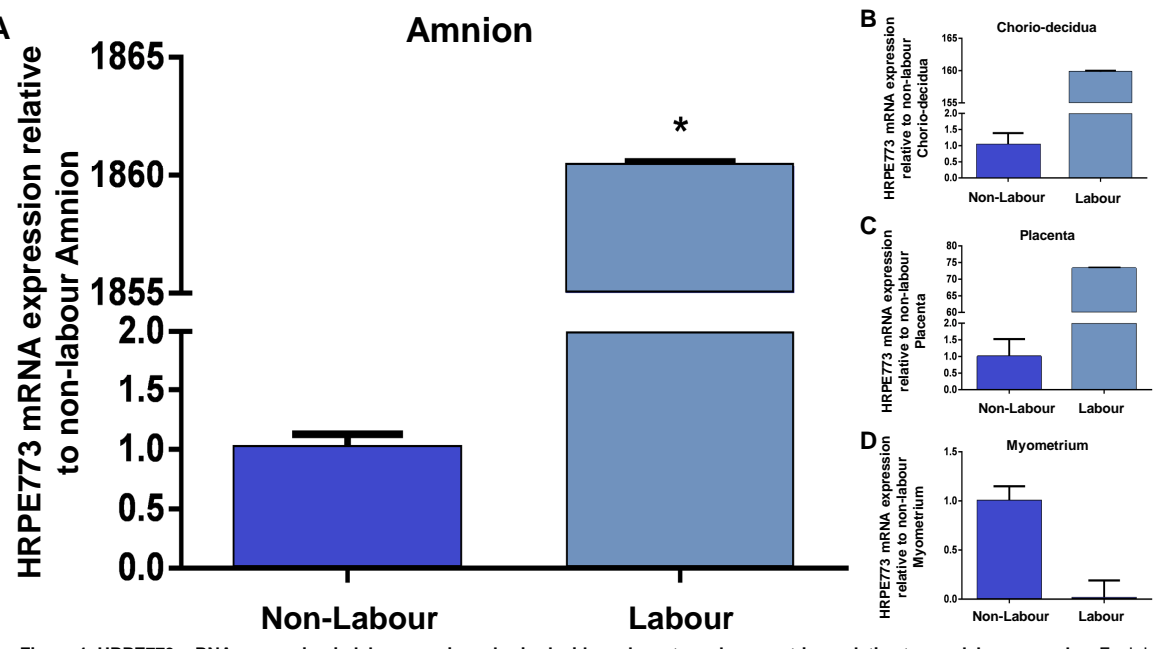

Figure 1. HRPE773 mRNA expression in labour amnion, chorio-decidua, placenta and myometrium relative to non-labour samples. Each bar represents the mean \pm SEM where $(n=3)$. A. Amnion. The asterisk denotes a statistically significant difference in HRPE773 mRNA expression in labour samples relative to non-labour counterparts according to Mann-Witney test $(p<0.05)$. B. Chorio-decidua. C. Placenta. D. Myometrium.

3
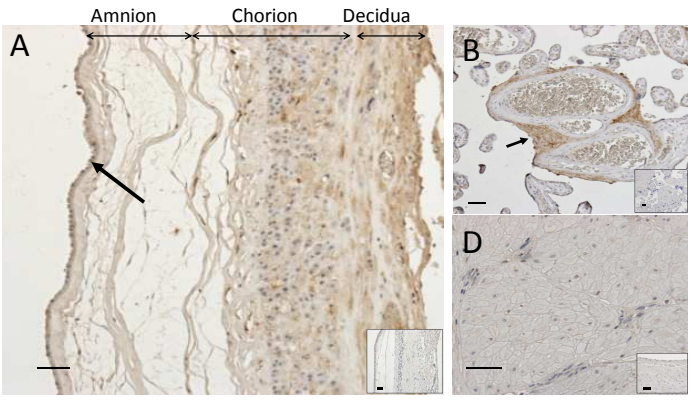

\section{C}

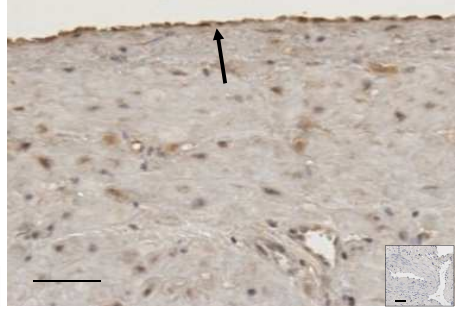

Figure 3. HRPE773 protein localisation in foetal membranes, placenta, myometrium and cervix. Scale bar represents $100 \mu \mathrm{um}$, (n=3). Negative
controls, using no primary antibody, are shown in bottom right hand corner $\mathbf{A}$. Foetal membranes (amnion, chorion \& decidua as labelled). Arrow controls, using no primary antibody, are shown in bottom right hand corner A. Foetal membranes (amnion, chorion \& decidua as labelled). Arrow
indicates epithelial immunostaining of amnion. B. Placenta. Arrow indicates immunostaining of fibrotic lesion. C. Cenvix. Arrow indicates epithelial staining. D. Myometrium. No staining.

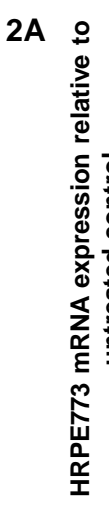

2B

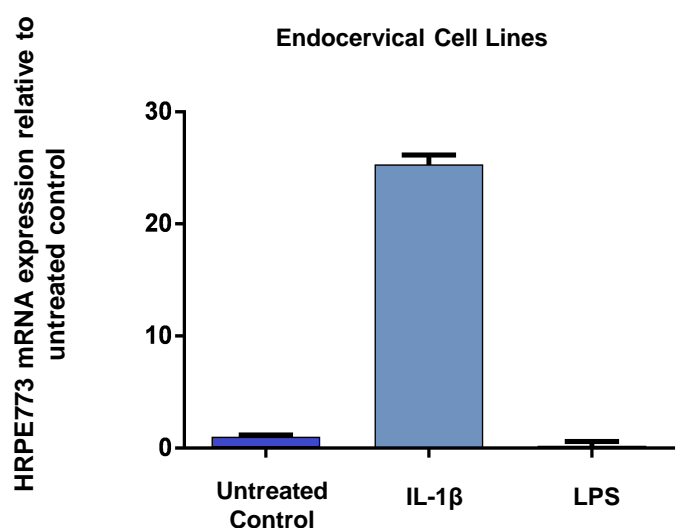

\section{Discussion}

- HRPE773 mRNA expression was significantly elevated in labour vs non-labour amnion, but not in other tissues examined (Fig. 1A-D).

- HRPE773 mRNA expression was significantly elevated following treatment with the inflammatory cytokine IL-I $\beta$ or LPS bacterial endotoxin in ectocervical, but not endocervical cell lines (Fig. 2A-B).

- HRPE773 protein was largely localised to epithelial surfaces in foetal membranes, placenta and cervix (Figs. 3A-C).

\section{References}

Shim SS, Romero R, Hong JS, Park CW, Jun JK, Kim BI, Yoon BH (2004). Clinical significance of intra-amniotic inflammation

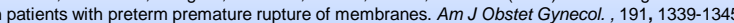

Ng KYB, McDonald SE, Ren X, Mullins JJ, Rae MT, Critchley HOD, Horne AW, Morley SD (2011). HRPE773 (ZG16B) expression is elevated in human endometrium during the early secretory phase and in uterine decidua following miscarriage. 